\title{
Novel improvement in processing of polymer nanocomposite based on 2D materials as fillers
}

\author{
P. A. R. Muñoz ${ }^{1}$, C. F. P. de Oliveira ${ }^{1}$, L. G. Amurin ${ }^{1}$, C. L. C. Rodriguez ${ }^{1}$, D. A. Nagaoka ${ }^{1}$, \\ M. I. B. Tavares ${ }^{2}$, S. H. Domingues ${ }^{1}$, R. J. E. Andrade ${ }^{1}$, G. J. M. Fechine ${ }^{1 *}$ \\ ${ }^{1}$ Graphene and Nanomaterials Research Center - MackGraphe, Mackenzie Presbyterian University, \\ Rua da Consolação, 896, SP, 01302-907 São Paulo, Brazil \\ ${ }^{2}$ Instituto de Macromoléculas Professora Eloisa Mano - IMA, Universidade Federal do Rio de Janeiro, \\ RJ, 21941-970 Rio de Janeiro, Brazil
}

Received 14 March 2018; accepted in revised form 28 May 2018

\begin{abstract}
Here, for the first time, novel improvement in processing of polymer nanocomposite based on 2D materials as fillers leading to manufacturing by melt mixing is described. Two new strategies were used to insert pre-exfoliated 2D material into the polymer matrix, liquid-phase feeding (LPF), and solid-solid deposition (SSD). Initially, graphene oxide (GO) and polystyrene (PS) were used as templates for the 2D material and polymer, respectively. Traditional characterizations (tensile mechanical test, molecular weight, rheological measurements and transmission electron microscopy) were carried out, therefore, two unique characterization techniques beyond micro and nanoscale were also used allowing the evaluation of the nanocomposite morphology for millimeter samples size (X-ray Microtomography and Low-Field Nuclear Magnetic Resonance). The results show that both methods could be suitable as large-scale manufacturing, and the process parameters must be optimized to obtain a low level of agglomerates. SSD and LPF methods were also applied to other different polymer/2D materials systems (poly(butylene adipate-co-terephthalate) - PBAT/GO and PS/Molybdenum disulfide - $\mathrm{MoS}_{2}$ ), and the results are also presented here. The methodologies described here show indications that can be extended to all thermoplastic polymers and 2D materials providing nanocomposites with suitable morphology to obtain singular properties and to trigger the start of the manufacturing process on a large scale.
\end{abstract}

Keywords: nanocomposites, $2 D$ materials, characterization, processing technologies

\section{Introduction}

In 2004, a single-crystalline graphite film of atomic thickness was isolated [1]. The researchers responsible for this revolutionary work, Novoselov and Geim, were shortly thereafter awarded the Nobel Prize in Physics for 'innovative experiments with graphene' in 2010. Several researchers have used graphene (Gr), graphene oxide (GO), and reduced graphene oxide ( $\mathrm{rGO}$ ) as mechanically reinforcing nanoparticles in polymeric matrices. The insertion of these two-dimensional (2D) materials considerably improves the mechanical properties of the polymers.
They also increase the thermal and electrical conductivity and the dimensional stability of the composite when compared to the polymer matrix [2-7]. Important challenges still need to be overcome to produce polymer nanocomposites based on two-dimensional particles (graphene-based materials, molybdenum disulfide, hexagonal boron nitrite, and phosphorene among others) on a large scale. Essentially, there are three strategies for nanocomposites preparation: 1) solution mixing, 2) in situ polymerization, and $3)$ melt mixing. The first two options achieve excellent results in terms of particles dispersion, however, 
the scale-up of these methods to industrial production is limited. Melt mixing is the only one that can be easily scaled-up using equipment such as a twinscrew extruder as part of a plastic production line. Most of the studies related to polymer nanocomposites based on 2D materials as fillers is one that solution mixing approach is used $[3,8]$.

The most important advantage of two-dimensional (2D) particles is their large surface area that enhances the interface with the polymer. This peculiarity leads to significant improvements in different properties of the polymer matrix with the insertion of very small contents of particles, which may not reach $2 \%$ by mass $[6,7,9-12]$. However, if the dispersion is not efficient, the re-stacking of the 2D material sheets occurs in excessive amounts, and the above-mentioned advantage is lost. In the case of twodimensional particles, the high dispersion degree in the polymeric matrix by using melt mixing process might turn in a challenge due to the need for tuning the processing conditions (screw speed, residence time of the 2D particles, processing temperature, and shear stress) for the singular shape of 2D particles. Besides that, there are the van der Walls forces between the layers that can induce particle agglomeration, which will negatively affect the desirable properties [13]. Therefore, there is a need to develop novel processes to obtain polymer/2D materials nanocomposites, with the possibility of scale-up feasibility for industry, which are extremely important for the manufacture of products with singular properties, keeping low levels of particle content and high levels of dispersion, with the aim to maintain a competitive production cost.

Here, we describe, for the first time, novel strategies based on systematic and fundamental studies, that present results about how 2D materials are inserted into a polymeric matrix in order to obtain nanocomposites using a conventional polymer processing equipment (extruder) leading to large-scale manufacturing. Initially, the graphene oxide (GO) and polystyrene (PS) were used as templates for the 2D material and polymer, respectively. Firstly, the graphite oxide (Gr-O) and GO was produced and characterized to obtain information about the level of oxidation and size of the particles before the processing with the polymer. Two new strategies were used to insert pre-exfoliated GO into the polystyrene, liquidphase feeder (LPF) and solid-solid deposition (SSD).
An experimental design was built to evaluate the effectiveness of these strategies in order to verify the homogeneity and dispersion of the 2D particles in the polymer matrix. The experimental design is based on the amount of GO and screw velocity in the PS/GO nanocomposite processing, analyzing the tensile mechanical properties of the materials produced. Additional characterizations were also used to evaluate nanocomposite morphology (molecular weight, rheological measurements and transmission electron microscopy) and two unique characterization techniques beyond micro and nanoscale were also used allowing the evaluation of the nanocomposite morphology for millimeter samples size (X-ray Microtomography and Low-Field Nuclear Magnetic Resonance). The evidence for effectiveness of the strategies can be confirmed by the presentation of the results from other different polymer/2D materials systems, poly(butylene adipate-co-terephthalate) - PBAT/GO and polystyrene/Molybdenum disulfide - $\mathrm{PS} / \mathrm{MoS}_{2}$.

\section{Experimental}

\subsection{Preparation and characterization of graphite oxide (Gr-O) and graphene oxide (GO)}

Firstly, the graphite oxide (GrO) was prepared following the modified Hummer's method [14] decreasing the oxidation time from 2 to 1 hour to produce a material with low level of oxidation. It was used with graphite flakes purchased from SigmaAldrich with nominal size $<150 \mu \mathrm{m} .200 \mathrm{mg}$ of graphite oxide $(\mathrm{GrO})$ were exfoliated into deionized water, using an ultrasonic bath (Elma, P30) for $30 \mathrm{~min}$ in individual $100 \mathrm{~mL}$ batches, in order to obtain a $2 \mathrm{mg} \cdot \mathrm{mL}^{-1} \mathrm{GO}$ suspension. To avoid precipitation, the GO suspension was constantly stirred ( $\sim 350 \mathrm{rpm})$ until the required suspension was obtained.

\section{Atomic force microscopy (AFM)}

Drop casting of GO dispersion was prepared on top of fresh mica and analyzed in an Icon Dimension (Bruker) equipped with RTESPA. In order to obtain a good statistic, more than 800 particles were counted and measured using Gwyddion Software.

\section{Raman confocal microscopy}

Raman spectra were acquired with a WITec Alpha 300R confocal Raman spectrometer. The excitation source was a $532 \mathrm{~nm}$ laser. 
Thermo-gravimetric analysis (TGA)

The thermal stability of graphite and graphite oxide was characterized using thermogravimetric analysis (DSC/TGA Q600, TA Instruments). All measurements were conducted under an inert atmosphere over a temperature range of $30-1000^{\circ} \mathrm{C}$ with a slow ramp rate of $10^{\circ} \mathrm{C} \cdot \mathrm{min}^{-1}$.

\section{$X$-ray diffraction analysis}

Analysis of graphite and Gr-O were performed in a Rigaku diffractometer with $\mathrm{K}_{\mathrm{Cu}}^{\alpha}$ radiation $(\lambda=1.42 \AA)$. The scan range used was from 5 to $70^{\circ}$ at rate scan of $0.083^{\circ} \cdot \mathrm{s}^{-1}$.

\subsection{Processing and characterization of PS/GO nanocomposites}

In order to produce a $\mathrm{GO} /$ polymer nanocomposite, two processing methods were tested using a corotational twin screw extruder $L / D=40$ (Process 11, ThermoScientific). The methods are based on solidsolid deposition (SSD) and liquid phase feeding (LPF) (Figure 1). For both methods homopolymer polystyrene was used donated by INOVA $\left(\bar{M}_{\mathrm{w}}=\right.$ $170603 \mathrm{~g} \cdot \mathrm{mol}^{-1}$ and $\left.P I=2.2\right)$. In SSD, polystyrene (PS) powder $(<600 \mu \mathrm{m})$ was added to a water dis- persion of graphene oxide with few layers (GO) $\left(1 \mathrm{mg} \cdot \mathrm{mL}^{-1}\right)$. The mixture was dried in the rotary evaporator equipment, resulting in PS powder covered by exfoliated GO particles. In the case of LPF, a liquid feeder operating by peristaltic pump with $\mathrm{GO}$ water dispersion $\left(1 \mathrm{mg} \cdot \mathrm{mL}^{-1}\right)$ was positioned on an extruder at $L / D=10$, in order to guarantee that the insertion of GO particles occurs when the polymer is in softened state. The pump flow rate was controlled to adjust the GO concentration. In both cases the focus was to introduce particles of GO already exfoliated into polymer matrix, since the extruder is not able to exfoliate the graphite oxide to GO. $4 \mathrm{~g} \cdot \mathrm{min}^{-1}$ feeding rate was adopted for all runs and the temperature profile used was: $170 / 230 / 250 / 250 / 260 / 230{ }^{\circ} \mathrm{C}$ from hopper to die.

\section{Injection molding}

Test specimens were produced using a barrel miniinjection molding machine (MiniJet Pro, ThermoScientific) using an ASTM Type V test specimen mold. Temperatures were 230 and $60^{\circ} \mathrm{C}$, for barrel and mold, respectively. An injection pressure of $200 \mathrm{MPa}(30 \mathrm{~s})$ and post-pressure of $150 \mathrm{MPa}(20 \mathrm{~s})$ were applied.

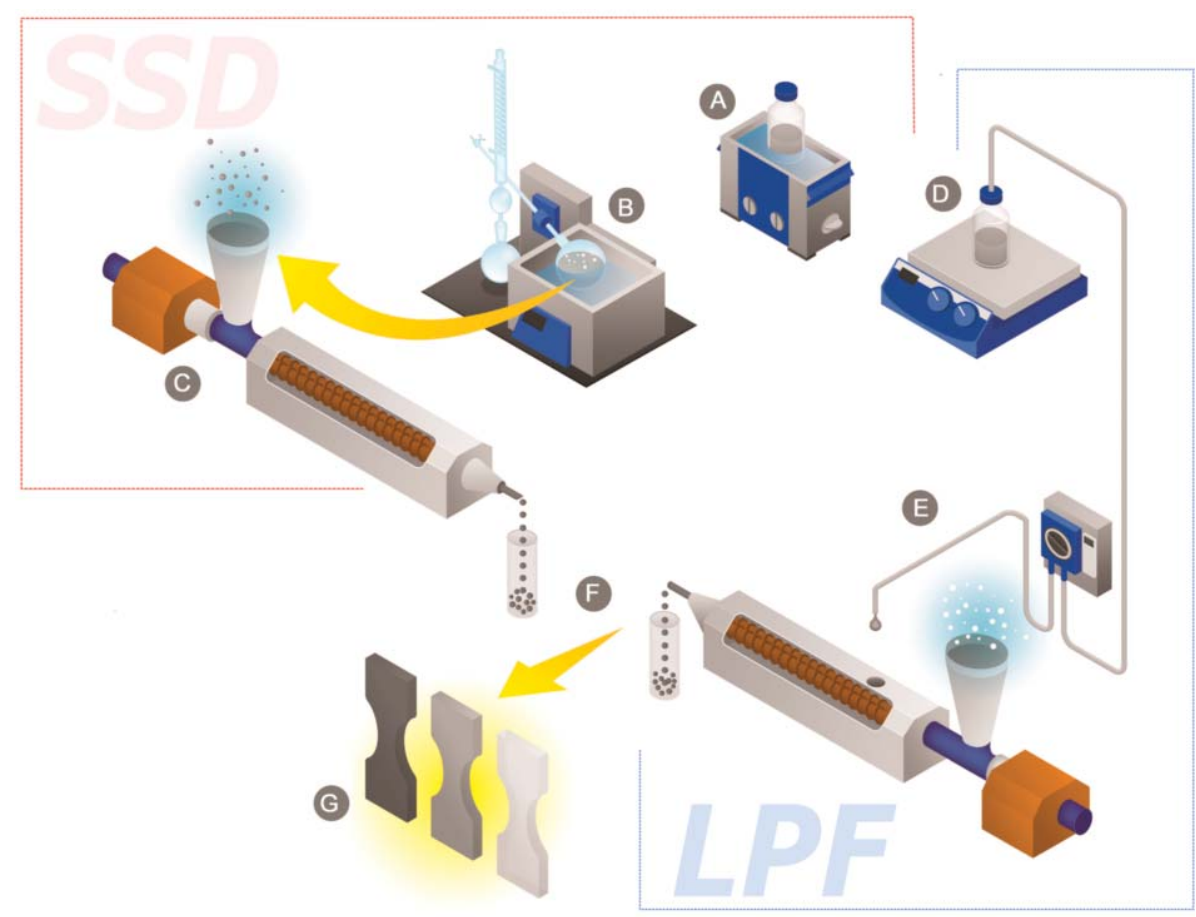

Figure 1. Schematic of SSD and LPF methods, developed for 2D/polymer composite processing at a high production rate. A: Graphite oxide exfoliation in water $\left(2 \mathrm{mg} \cdot \mathrm{mL}^{-1}\right)$. B: GO particles are deposited onto PS powder surface using a rotavapor equipment. C: PS powder covered by GO been placed directly into extruder feeder. D: GO suspension is continuously stirred to avoid precipitation at $350 \mathrm{rpm}$. E: GO suspension is pumped directly onto melted PS at $L / D=10$ in a twin-screw extruder. F: Polymeric composites pelletizing. G: Specimens production using Injection molding (Type-V ASTM). 
Mechanical properties measurement

Tensile tests were performed in a universal Zwick test Machine at a deformation rate of $1 \mathrm{~mm} \cdot \mathrm{min}^{-1}$ at room temperature $\left(25^{\circ} \mathrm{C}\right)$.

\section{Molecular weight measurements}

Molecular weight and its distribution were measured using a size exclusion chromatograph (Malvern) equipped with an RI detector. All samples were analyzed in THF at $40{ }^{\circ} \mathrm{C}$ with $0.25 \%$ of BHT. $1 \mathrm{~mL} \cdot \mathrm{min}^{-1}$ solvent flow was used in both pumps and calibration was performed using mixed PS standards (PolyAnalytik) from $1.5 \mathrm{kDa}$ to $4 \mathrm{MDa}$. All samples were filtered using $0.45 \mu \mathrm{m}$ syringe filter.

\section{$X$-ray microtomography}

Pieces of at least $2 \mathrm{~mm} \times 2 \mathrm{~mm} \times 2 \mathrm{~mm}$ from tensile strength specimens were used for characterization. Samples were analyzed in a SkyScanner 1272 (Bruker), using $20 \mathrm{kV}$ and $175 \mu \mathrm{A} \mathrm{X}$-ray source, with a final image resolution of $2 \mu \mathrm{m} /$ pixel.

\section{Low-field nuclear magnetic ressonance}

The proton spin-lattice relaxation time $T_{1} H$ of the sample was analyzed in a Maran Ultra 23 (Oxford), operating at $23 \mathrm{MHz}$ for protons, equipped with
$18 \mathrm{~mm}$ NMR tube. The pulse sequence used to determine the relaxation data was inversion-recovery. The 90 degree was $7.6 \mu$ s, which was automatically calibrated by the equipment software. The amplitude of the FID was sampled for $40 \tau$ data point varying from 0.1 to $10000 \mathrm{~ms}$ with four scans each and $10 \mathrm{~s}$ of recycle delay. The values of $T_{1} H$ were obtained by fitting the exponential data using the Winfit program that comes with the spectrometer.

\section{Rheological test in steady state}

Disc-like specimens were prepared by compression molding at $230^{\circ} \mathrm{C}$, with 3 tons of pressure for 2 minutes. Rheological tests under rotational flow were performed in an Anton Paar 102 rheometer with controlled strain, using plate/plate geometry, $1 \mathrm{~mm}$ gap at $230^{\circ} \mathrm{C}$ and shear rate from 0.01 to $10 \mathrm{~s}^{-1}$.

\section{Transmission electron microscopy (TEM)}

TEM imaging was performed on a JEOL 1200 EXII microscope at $8 \mathrm{keV}$. Samples with $60 \mathrm{~nm}$ thickness were collected on top of 200 mesh-copper grids.

\section{Results and discussion}

The first step in the present project was graphene oxide (GO) synthesis through graphite oxidation.

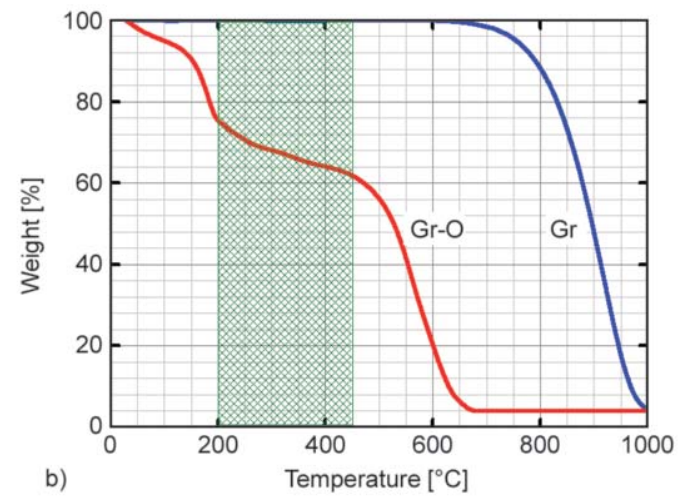

a)

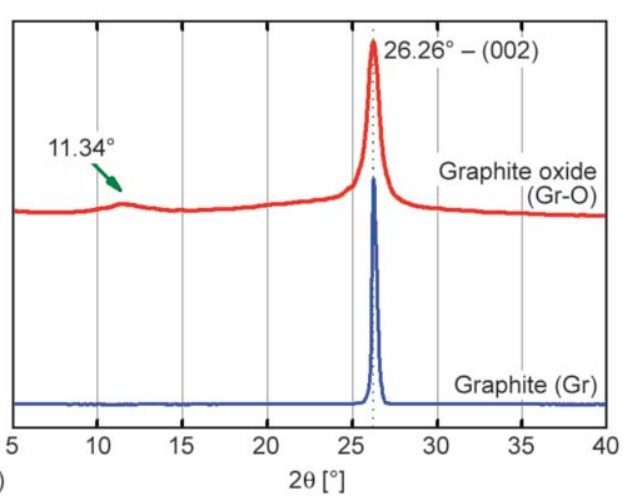

b)

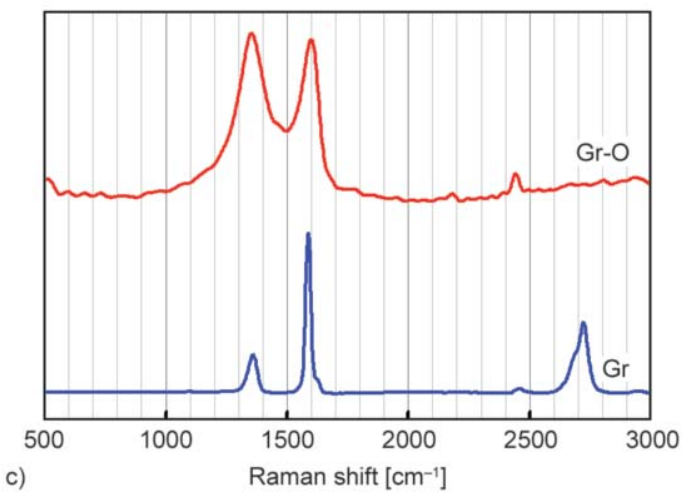

Figure 2. Gr-O characterization. (a) XRD pattern. (b) Weight loss in an inert atmosphere (heating rate: $10^{\circ} \mathrm{C} / \mathrm{min}$ ). (c) Raman spectra (excitation laser: $532 \mathrm{~nm}$ ). 
The modified Hummer's method was used to graphite oxidation and the material obtained was characterized using X-ray diffraction (XRD), thermal gravimetric analysis (TGA) and Raman spectroscopy. The graphite oxide (Gr-O) is expected to be the material obtained by Hummers's Method following by liquid phase exfoliation (LPE) to prepare graphene oxide (GO) dispersion. Gr-O characterizations are presented in Figure 2.

In XRD (Figure 2a) it is possible to observe a diffraction peak in $\mathrm{Gr}-\mathrm{O}$ at $11.34^{\circ}$, indicating an aperture of (002) graphitic planes, originally at $26.26^{\circ}$ for graphite, caused by the introduction of oxygenated groups during oxidation [15]. As more oxygenated group are inserted, the intensity of the peak at 26 is decreased (comparing to the graphite XRD pattern) and the distance of the 002 plane is increased generating a peak around $10-11^{\circ}$. High level of graphite oxidation can turn almost all peak at $26^{\circ}$ into $\sim 10^{\circ}$ [16]. The presence of oxygenated groups along graphitic structure turn it less stable than neat graphite resulting a weight loss observed in the region between 200 and $450^{\circ} \mathrm{C}$ (Figure 2b) $[17,18]$, while graphite is stable until near to $700^{\circ} \mathrm{C}$. Finally, Raman spectroscopy also confirms the graphite oxidation, as an increase is observed in the D band $\left(\sim 1350 \mathrm{~cm}^{-1}\right)$. Increase of $\mathrm{D}$ band is caused by the broken symmetry due to the presence of oxygenated groups and to new boundaries generated by flake breakage during the exfoliation of Gr-O. Level of oxidation is also a very important parameter in terms of particle dispersion, as the presence of oxygenated groups causes changes in the surface energy. Here, Gr-O synthesis was designed to obtain low oxidation level GO, and this is confirmed by low intensity of $11.34^{\circ}$ peak in Gr-O XRD pattern (Figure 2a), low loss weight between 200 and $450^{\circ} \mathrm{C}(\sim 13 \%)$ and by the ratio between $\mathrm{D}$ band and $\mathrm{G}\left(\sim 1600 \mathrm{~cm}^{-1}\right)$ band of $\mathrm{Gr}-\mathrm{O}$ be near to unity

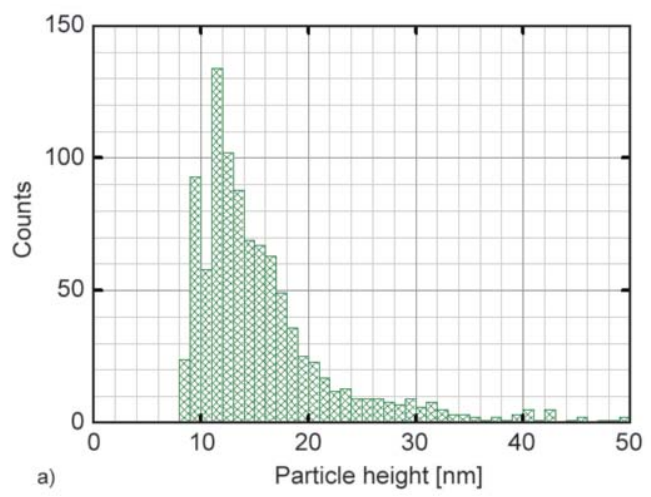

(Figure 2c) [15]. A low oxidation-level Gr-O was chosen to obtain a better interaction with the polymeric matrix during the processing as PS presents low polarity. If high oxidation-level Gr-O was chosen the phase separation on composites could be higher due to the incompatibility between polymer and GO.

Once Gr-O was successfully produced, it was exfoliated in deionized water before introduction into polymeric matrix. These exfoliated particles were characterized by atomic force microscopy (AFM) using samples prepared on top of fresh mica. Figure 3 shows topographic mapping obtained by AFM and measurements of particles geometrical characteristic were done by counting 1001 particles using Gwyddion software.

Through AFM image (Figure 3) is possible to observe particles with very different heights and sizes, it is a consequence of cavitation during LPE using ultrasonication, that leads to fragmentation and then to its exfoliation $[19,20]$. All particles were selected by height by using Gwyddion software (threshold height: $0.75 \mathrm{~nm}$ ), then a statistical particle routine was executed to obtain distribution curves for height and lateral size (Figure 3). As can be observed in Figure 3, most of the particles presents height lower than $20 \mathrm{~nm}$, mean was estimated to be $17 \mathrm{~nm}(<20$ layers $)$, i.e., our starting material is in fact a few-layer GO thus in bidimensional scale. Lateral size measurements (Figure 3) shows a great size reduction of particles, as initial graphite flakes had a mean size of $150 \mu \mathrm{m}$ and the final mean lateral size is about $400 \mathrm{~nm}$.

\subsection{Experimental design analysis: Effect of \%GO and screw velocity in PS/GO nanocomposite tensile mechanical properties.}

SSD and LPF methods were evaluated using a mixed 2 and 3 levels experimental design to understand the

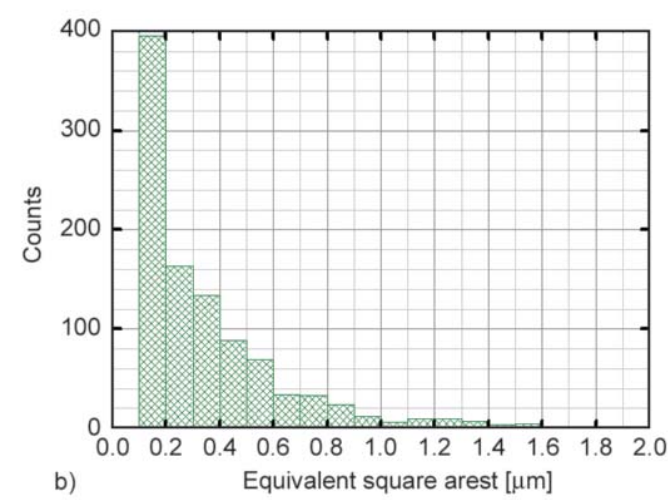

Figure 3. (a) Particle height and (b) square root area distribution for GO suspension. 
Table 1. Processing PS/GO composite experimental design.

\begin{tabular}{|c|c|c|c|c|}
\hline Run & \%GO & SV & $\begin{array}{c}\text { \%GO } \\
{[\mathbf{w t} \%]}\end{array}$ & $\begin{array}{c}\text { SV } \\
{[\mathbf{r p m}]}\end{array}$ \\
\hline 1 & + & + & 0.5 & 350 \\
\hline 2 & + & - & 0.5 & 250 \\
\hline 3 & 0 & + & 0.3 & 350 \\
\hline 4 & 0 & - & 0.3 & 250 \\
\hline 5 & - & + & 0.1 & 350 \\
\hline 6 & - & - & 0.1 & 250 \\
\hline
\end{tabular}

$(+)$ upper variable level

$(-)$ lower variable level.

(0) central point.

effects of screw velocity (SV) and GO particles amount on the tensile properties of PS/GO composites (Table 1). Young's Moduli (YM), TS (Tensile Strength) and SBP (Strain at the Break Point) were obtained from tensile-strain plots of PS and PS/GO composites prepared by SSD and LPF methods following experimental conditions described on Table 1. Surface response was obtained using ANOVA with $5 \%$ of significance-level and random error distribution.

The TS (Tensile Strength) and SBP (Strain at the Break Point) data show high variation and the $R^{2}$ values are quite low for these two mechanical properties (Table 2 and Table 3). This high variation is
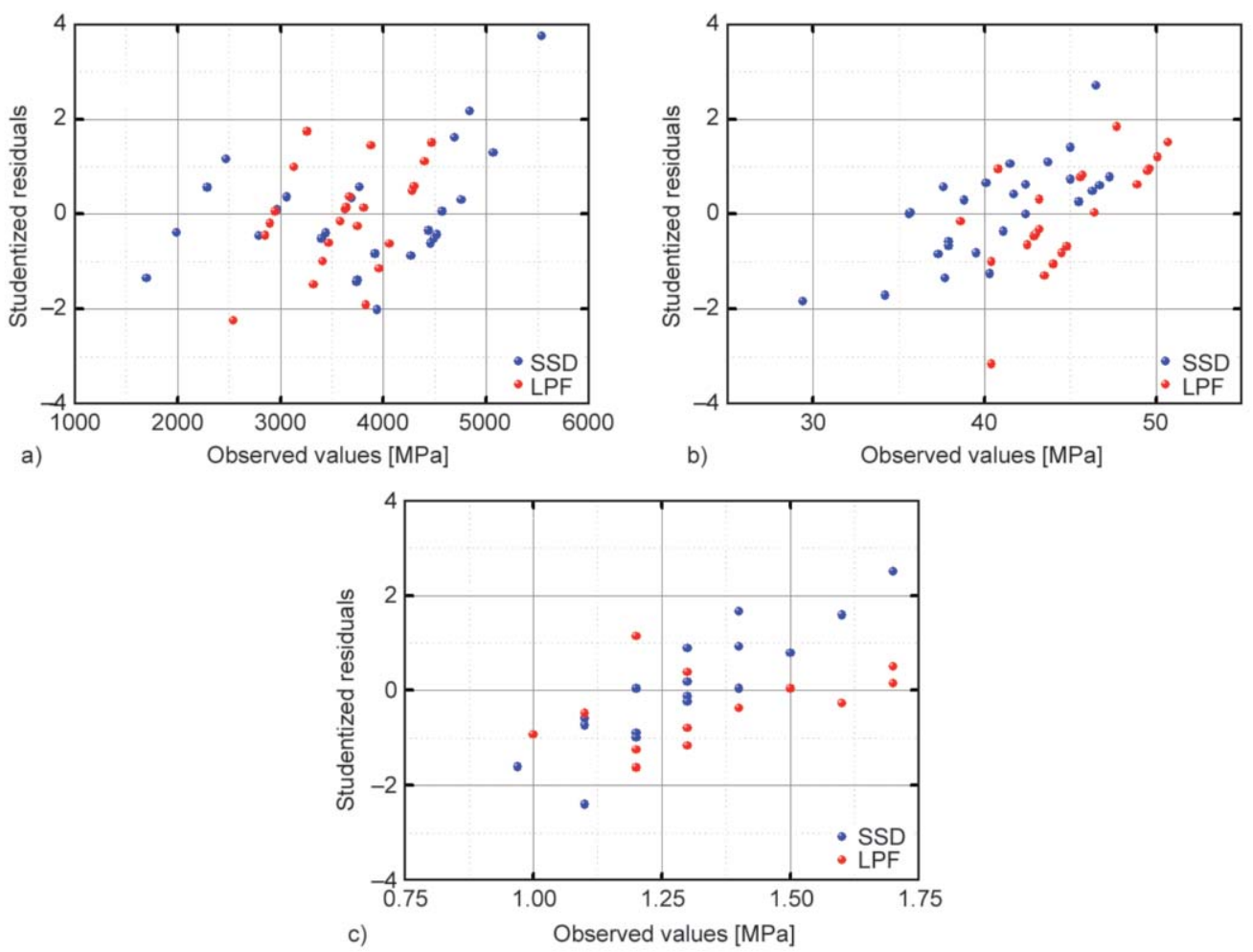

Figure 4. Residual plots of SSD and LPF surface responses by ANOVA $(\alpha=0.05 \%)$ : (a) Young' moduli, (b) tensile strength and (c) strain at breaking point. 
probably due to $\mathrm{GO}$ agglomerates obtained during processing. Polystyrene is a brittle polymer and the presence of agglomerates increases the probability of break caused by interfacial defects. Residual plots (Figure 4) shows that only Young's Moduli present a random error distribution while TS and SBP present a quasi-linear increase in residuals with the increase in observed values, i.e., the model error increase in non-random way creating an error tendency in statistical model. As statistical models for TS and SBP did not present random error distribution, these surfaces cannot be considered valid. The rigidity of PS and defects induced by GO agglomeration must have induced this result. The TS is strongly influenced by interfacial defects that leads to structure collapses during the tensile test. The same observation is valid for SBP since the fact of neat PS shows low ductility ( $\mathrm{SBP}<2 \%$ ).

Table 4 shows the results about the regression coefficients of response variables for the different nanocomposite manufacturing routes studied by ANOVA. As can be observed $R^{2}$ values are lower than 1, it happens because surface responses were calculated using ANOVA method and not a fitting method, once the last did not present statistical meaning. In order to understand the responses only Young's Moduli response was chosen for both system, once presented the higher $R^{2}$ values $(>0.85)$.

Surface responses for Young's Moduli (YM) to both methods are presented in Figure 5, where it is possible to observe that \%GO and SV display different effects on the mechanical performance of the nanocomposite for both methods. In the case of SSD method, there is a discontinuous influence of GO content in $\mathrm{YM}$ when screw velocity of $250 \mathrm{rpm}$ is chosen, in fact a local minimum at surface at $0.3 \%$ of GO is shown. At this point, probably, there is a change in particle aggregation from nano-domains $(<0.3 \% \mathrm{GO})$ to micro-domains $(>0.3 \% \mathrm{GO})$, due to particle segregation during processing. However, at high screw velocity level (350 rpm), the YM values are higher than neat and processed PS ( $4000 \mathrm{MPa})$ and they are not affected by the variation of GO content, probably due to better distribution and dispersion caused by higher shear rate generated by twin-screw shear flow. High level of particle dispersion increases

Table 4. Regression coefficients of response variables for the different nanocomposite manufacturing routes studied by ANOVA.

\begin{tabular}{|c|c|c|c|c|c|c|c|c|c|}
\hline Model: & \multicolumn{9}{|c|}{$S=a_{0}+a_{1}(\% \mathrm{GO})+a_{2}(\% \mathrm{GO})^{2}+a_{3}(\mathrm{SV})+a_{4}(\mathrm{SV})^{2}+a_{5}(\% \mathrm{GO})(\mathrm{SV})+a_{6}(\% \mathrm{GO})^{2}(\mathrm{SV})$} \\
\hline Sample & Variable & $a_{0}$ & $a_{1}$ & $a_{2}$ & $a_{3}$ & $a_{4}$ & $a_{5}$ & $a_{6}$ & $R^{2}$ \\
\hline \multirow{3}{*}{ SSD } & $E \quad[\mathrm{MPa}]$ & 3198.7 & -56406.2 & 108187.5 & 4.1 & - & 163.3 & -318.2 & 0.86933 \\
\hline & TS $[\mathrm{MPa}]$ & 27.31640 & -380549 & - & 0.05107 & - & - & -0.04024 & 0.43576 \\
\hline & SBP [\%] & 1.1167661 & - & - & 0.000804 & - & - & -0.002649 & 0.35466 \\
\hline \multirow{3}{*}{ LPF } & $\begin{array}{ll}E & {[\mathrm{MPa}]}\end{array}$ & 4665.2 & -12944.1 & 27895.2 & - & - & - & -15.7 & 0.85028 \\
\hline & {$[\mathrm{MPa}]$} & 60.1861 & - & - & -0.0500 & - & - & - & 0.75152 \\
\hline & SBP [\%] & 2.794921 & - & - & -0.004351 & - & -0.001745 & - & 0.52037 \\
\hline
\end{tabular}
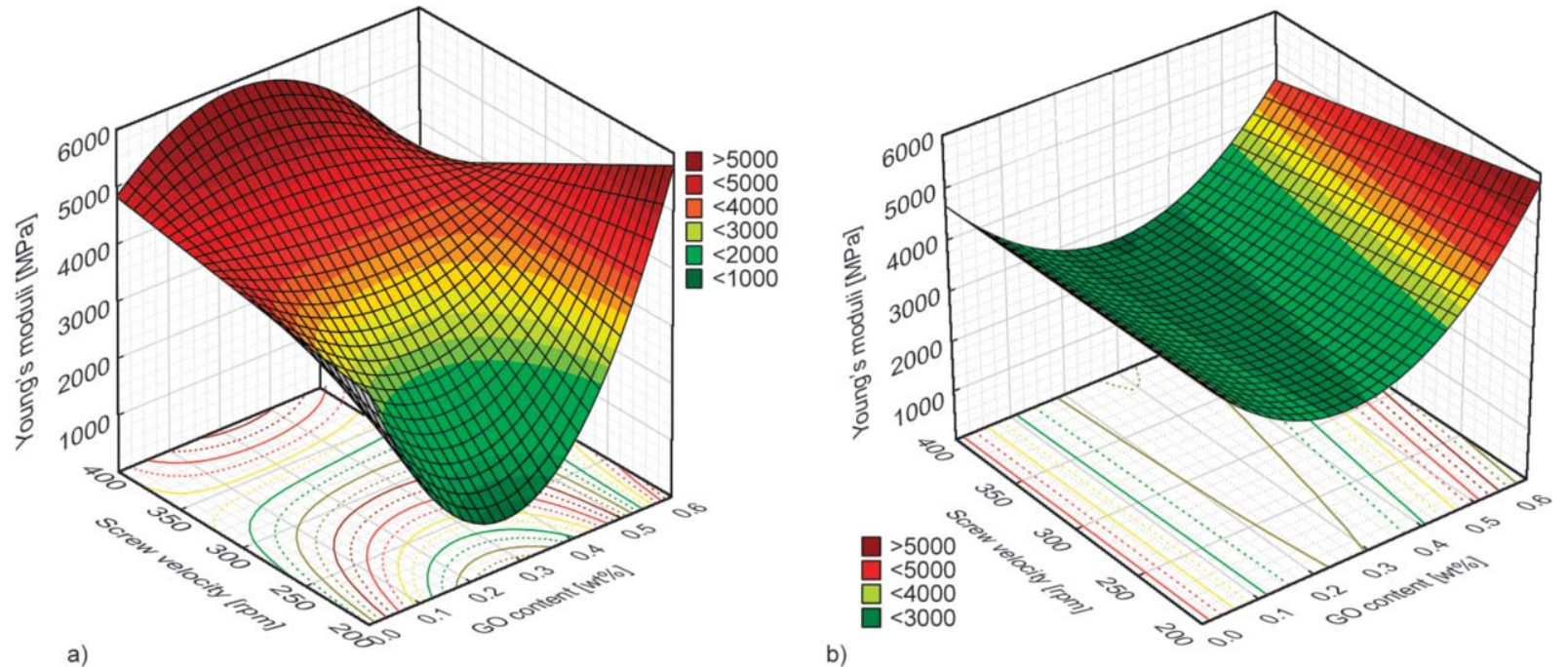

Figure 5. Young's Moduli response surfaces for composites produced by (a) SSD and (b) LPF methods. 
the surface area in contact with the polymer and an interphase zone is formed around each particle modifying the polymer chain mobility [10], and YM is affected positively when compared to neat and processed PS. Looking at the influence of screw velocity for all compositions, YM tends to increase with higher SV due to better mixing between particle and polymeric matrix, which may indicate that lower level of particles aggregates has occurred.

Note that the data for LPF was completely different, presenting a minimum local of YM at low and high screw velocity levels, showing a quadratic dependence of YM as function of GO content. Increments in GO amount tends to increase particle agglomeration, however particles in micro-scale must present a minimal critical length to have some effect in matrix. In contrast to SSD method, the LPF method presents a decrease of YM values for all range of GO content when SV is increased. According to the method, the $\mathrm{GO}$ dispersion is inserted to the extruder at $\sim 240^{\circ} \mathrm{C}$ generating a very fast evaporation of water molecules, probably, inducing GO particles agglomerates into the system. Therefore, the increasing of SV probably drag the suspension drops into polymeric flow and after water evaporation the GO particles are restacked and some agglomerates can be formed.

In order to compare the methods, a difference response surface was calculated by using the statistical models, as presented in Equation (1). The resulting surface was calculated by the difference of the response surfaces. The new response surface is presented on Figure 6 and shows that there is a great difference in YM for composites depending of processing method applied:

$\mathrm{SR}_{\mathrm{d}}=\mathrm{SR}_{\mathrm{LPF}}+\mathrm{SR}_{\mathrm{SSD}}$

where $\mathrm{SR}_{\mathrm{d}}$, is the difference between LPF surface response $\left(\mathrm{SR}_{\mathrm{LPF}}\right)$ and $\mathrm{SSD}$ surface response $\left(\mathrm{SR}_{\mathrm{SSD}}\right)$. According to surface responses difference it is possible to observe which method had good performance in different SV ranges. Apparently, LPF works better in low SV than SSD method. In SSD method, GO flakes are re-stacked due to water evaporation during rotary evaporator step, and probably at low SV extruder machine did not develop enough shear rate to break this stacked GO. When SV is increased SSD method works better than LPF, indicating that above $250 \mathrm{rpm}$ shear rate developing in the extruder machine is high enough to delaminate the GO

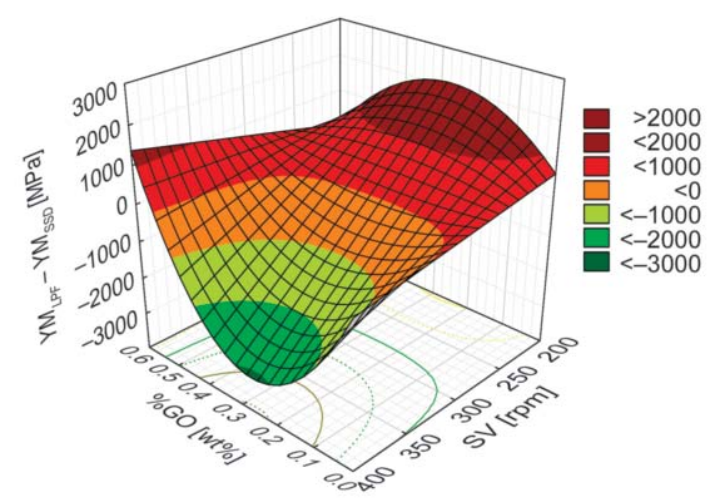

Figure 6. Young's Moduli surface difference between LPF and SSD methods.

agglomerates. In this situation, the nano-domains increase leading to a better mechanical performance.

Composites were compared with control samples of processed PS. Mechanical testing showed there is no difference between processed PS at 250 and $350 \mathrm{rpm}$. Analyzing composites processed at $250 \mathrm{rpm}$ (Figure 7a), there is no significant difference in Young's modulus when compared to the processed PS (dashed green line). On the other hand, composites processed at $350 \mathrm{rpm}$ (dashed red line) showed a Young's modulus higher than PS processed when the SSD approach was used (Figure 7b). The effect of an increase in Young's Moduli is caused by the presence of GO with a significantly dispersed particle distribution due to an increase in shear rate (screw velocity) that also leads to a better interface development. The aggregation/agglomeration of nanoparticles significantly decreased Young's modulus, whereas a fine dispersion of nanoparticles produced a high modulus values.

The SSD methodology presented about 24 and 13\% of increment in Young's modulus for 0.1 and $0.5 \%$ of GO, respectively. El Achaby et al. [21] and have showed an improvement of $36 \%$ for polypropylene Young's modulus with $0.5 \%$ wt of graphene nanoplates, similar results were also published [22, 23]. However, the equipment used in these studies was not a proper extruder, but an internal mixer with conical twin screw and material feedback flow. Increases in Young's modulus higher than 50\% were obtained by Fang et al. [24], but the authors reached this result through direct functionalization of graphene sheets with PS followed by processing. Increment of PS properties with nanofillers through extrusion processing is quite difficult, as can be observed by Oliveira and coworkers [11], in this case montmorillonite nanoclays were used. In situ polymerization 

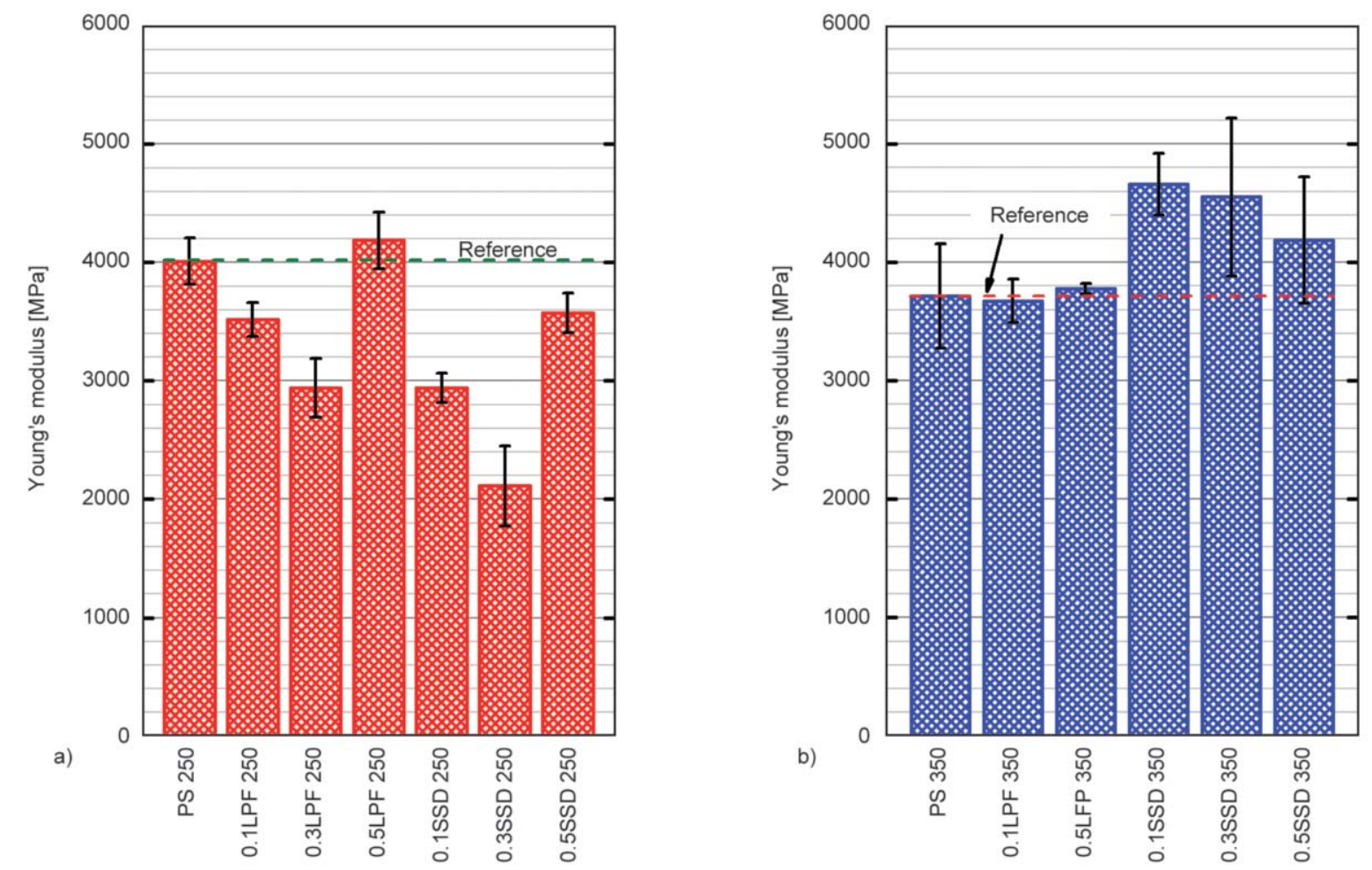

Figure 7. (a) Comparison of Young's modulus between composites and (b) PS processed at $250 \mathrm{rpm}$ and $350 \mathrm{rpm}$. Sample code: $X X$ YYY ZZZ (XX = GO content, YYY = method and ZZZ = screw velocity).

[25] and solvent mixing [26] techniques have also been used to prepare polymer nanocomposites but normally mechanical behavior is not the focus of these studies. It is really difficult to compare the results already published with those presented here, as the processing methods were different. Our methodologies are designed for a continuous production while others studies in the specialized literature were carried out with batch processing or by using solvent mixing focusing on electrical and barrier properties.

\subsection{Processing effects on nanocomposites structure}

Once different responses were obtained for the nanocomposites, a study regarding structural changes was performed to relate processing, structure and fundamental properties. The first structural characteristic studied was the PS molecular weight change during extrusion process of the nanocomposites. Mechanical response of polymeric materials is chain length dependent, as it influences chain entanglement changing properties in the elastic and plastic deformation regions. Molecular weight data of neat PS shows a slight reduction in $\bar{M}_{\mathrm{n}}$ and $\bar{M}_{\mathrm{w}}$ after extrusion caused by high shear rate and thermo-oxidation reactions occurred during the processing $[12,13,27]$. Values of
$\bar{M}_{\mathrm{n}}$ and $\bar{M}_{\mathrm{W}}$ of PS show a reduction for all nanocomposites prepared via SSD methodology at $350 \mathrm{rpm}$ when compared with neat PS but they are higher than processed PS (Figure 8a). The stabilizing effect may result from a GO lubricant action during the processing. Figure $8 \mathrm{~b}$ shows the difference in $\bar{M}_{\mathrm{n}}$ compared to processed PS for different routes with $0.5 \%$ of GO. As can be seen on Figure $8 \mathrm{~b}$, there is a stabilizing effect on the $\bar{M}_{\mathrm{w}}$ for all nanocomposite due to the GO presence. All raw molecular weight data are presented on Table 5.

Particle dispersion and distribution in the polymer matrix were analyzed by X-ray microtomography (XR-MT) and low-field nuclear magnetic resonance (LF-NMR). These techniques are beyond micro and nano-scale, giving the possibility to evaluate the morphology for millimeter samples size. Particle size was measured using XR-MT data. As particles inserted had sizes lower than $20 \mathrm{~nm}$, as showed by AFM, all micro-size particles are resulting from a segregation process that occurs during processing. In order to verify the homogeneity distribution by using XR-MT data, the projection of the position coordinates of particles $(x, y, z)$ inside the composite prepared by SSD method were plotted on Figure 9. Two composites are shown in this figure, 0.1 and $0.3 \%$ of GO prepared by SSD and $350 \mathrm{rpm}$. They were chosen because 

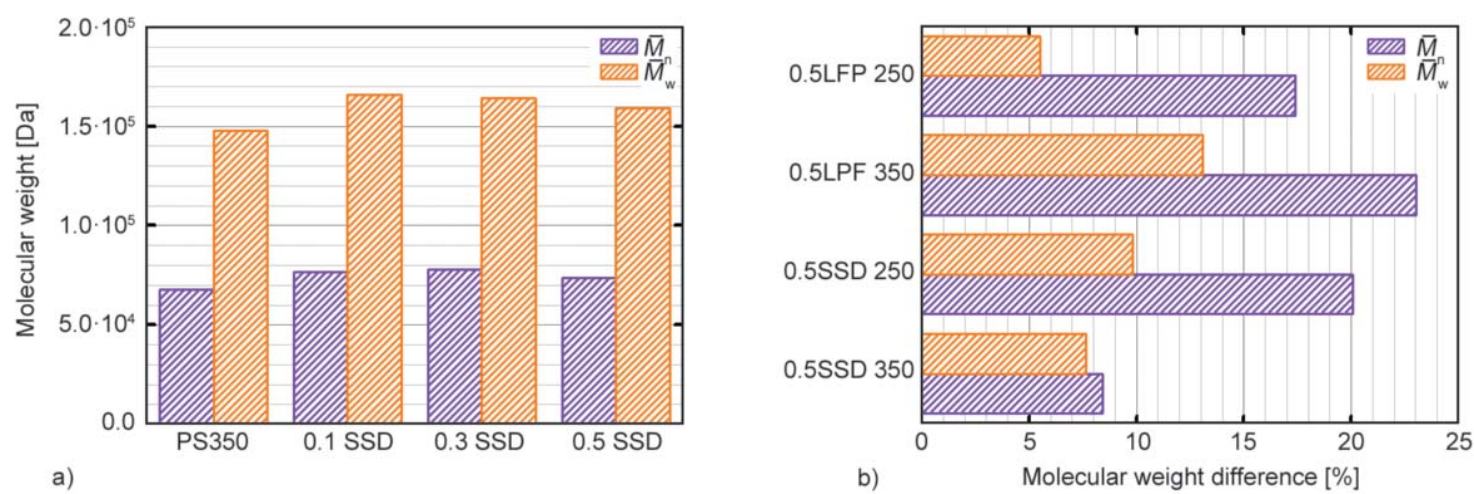

Figure 8. (a) Effect of \% GO in $\bar{M}_{\mathrm{n}}$ and $\bar{M}_{\mathrm{w}}$ of PS processed by SSD at $350 \mathrm{rpm}$. (b) $\bar{M}_{\mathrm{W}}$ difference of all nanocomposites produced with $0.5 \%$ of GO compared to processed PS. Samples code: XX YY ZZZ (XX = GO content, YYY = method and $\mathrm{ZZZ}=$ screw velocity).
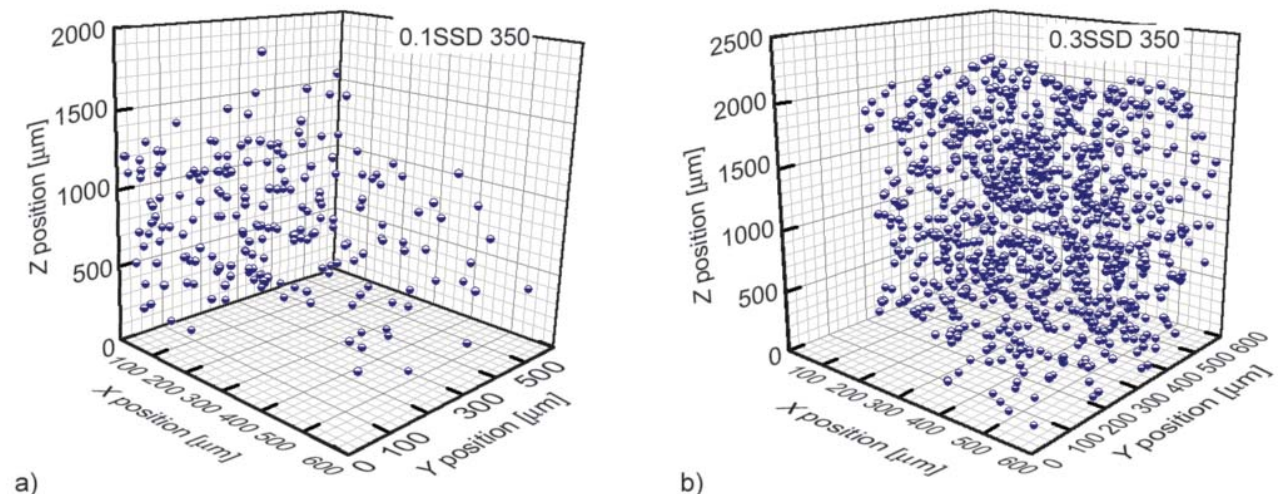

Figure 9. Projection of $(x, y, z)$ coordinates for GO particles inside composites (a) 0.1SSD 350 (lower particle density, 39 particles $/ \mathrm{mm}^{3}$ ) and (b) $0.3 \mathrm{SSD} 350$ (high particles density, 700 particles $/ \mathrm{mm}^{3}$ ).

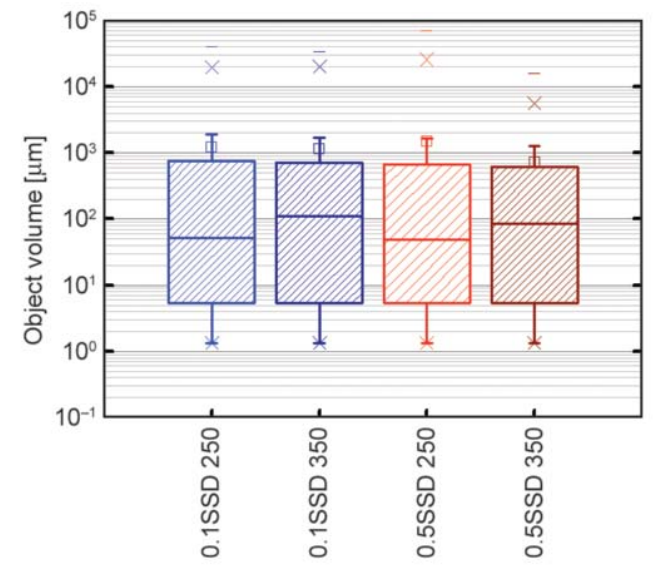

Figure 10. Box-plot of volume particles for SSD method at $0.1 \%$ and $0.5 \%$ of GO. (-) maximum or minimum observed value, $(\times)$ outlier, $(\square)$ mean.

they present good mechanical response (YM) which was attributed to low level of aggregates and good particles distribution. It can be seen that both of the composites present a good particle distribution along the composite volumes.

Figure 10 shows box-plot of particle volume distribution for SSD methods with $0.1 \%$ and $0.5 \%$ of GO. As can be observed, there is no significant difference

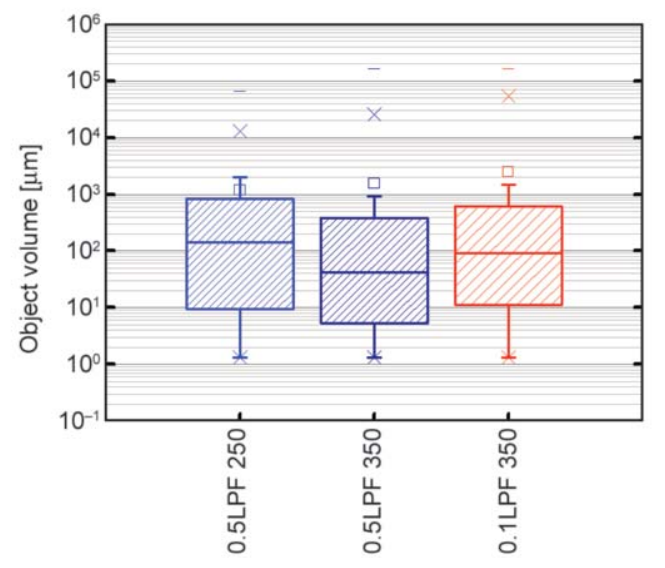

Figure 11. Box-plot of particle volume distribution for LPF method at $0.1 \%$ and $0.5 \%$ of GO. (-) maximum or minimum observed value, $(\times)$ outlier, $(\square)$ mean.

in volume distribution, however the number of aggregated formed are quite different. Low values of SV (250 rpm) induced number of GO particles aggregated slightly higher than at high SV (350 rpm), caused by low shear rate developed.

LPF method did also not show significant changes in particle volume distribution, as can be seen in 


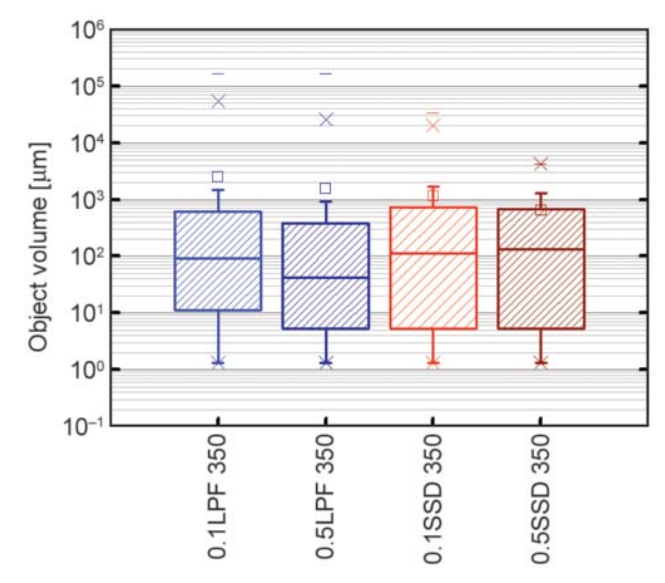

Figure 12. Box-plot of particle volume distribution comparison between LPF and SSD methods at $0.1 \%$ and $0.5 \%$ of GO content. (-) maximum or minimum observed value, $(\times)$ outlier, $(\square)$ mean.

Figure 11. In Figure 12 both methods are compared showing the presence of bigger particles in composites produced via LPF method. However, the number of observations to these particles are very low. Therefore, it can be assumed that both methods lead to particles with similar sizes and the main difference between them is the number of particles formed during processing. In this way all properties were related with particle density (PD), calculated according to Equation (2):

$\mathrm{PD}=\frac{\text { Number of particles }}{\text { VOI }}$

where VOI is the volume of interest, i.e., it is the selected volume used to analyze solid body tomography. All VOIs where chosen to avoid cracks formed during sample cutting, as they had a strong scattering effect. PD values are presented as mean of at least two VOI random chosen along sample.

The PD was obtained from XR-MT and its increase means the tendency of particle agglomeration. Data

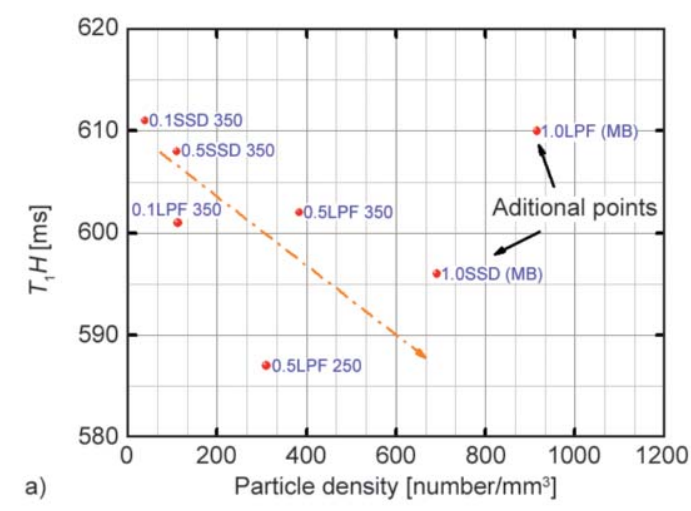

from XR-MT and LF-NMR are presented on Figure $13 \mathrm{a}$ to evaluate the spin-lattice relaxation/particle agglomeration correlation. There is a tendency of reduction of spin-lattice relaxation time (with a time constant $-T_{1} H$ ) with increase in particle density (PD) taking out two additional points containing $1.0 \% \mathrm{GO}$ (Figure 13a). High level of particle aggregation means less surface contact between polymer and GO, consequently polymer chains are free to move. According with the data showed in Figure 13b is also possible to affirm that high $E$ values are compatible with high $T_{1} H$, indicating a better interfacial adhesion between polymer matrix and GO particles. The polymer chains anchor onto GO particles and the spinlattice relaxation time is increased. Increase in $T_{1} H$ values with $\mathrm{SV}$, as well as increase in elastic modulus (as showed before) for nanocomposites prepared at $\mathrm{SV}$ of $350 \mathrm{rpm}$ indicate a better interface GO/polymer and a low level of particle aggregation (low PD, Figure 13a).

There is no direct relation between observed $T_{1} H$ values and molecular weight, and plotting TS and SBP as $T_{1} H$ function values no correlation also was found. As mentioned before, the brittleness of PS and structural failures caused by agglomerates formed during processing have great effect on mechanism involving plastic deformation due to lack of matrixparticles interaction. All XRMT and LF-NMR data are presented in Table 5.

In order to obtain indications regarding exfoliation and dispersion level as a function of the processing parameters rheological tests in steady shear flow were performed. Figure 14a presents the steady shear viscosity versus the shear rate for neat PS and its nanocomposites at the two different screw velocities during the processing by using SSD method. In Figure $14 \mathrm{a}$ the viscosity response of the materials

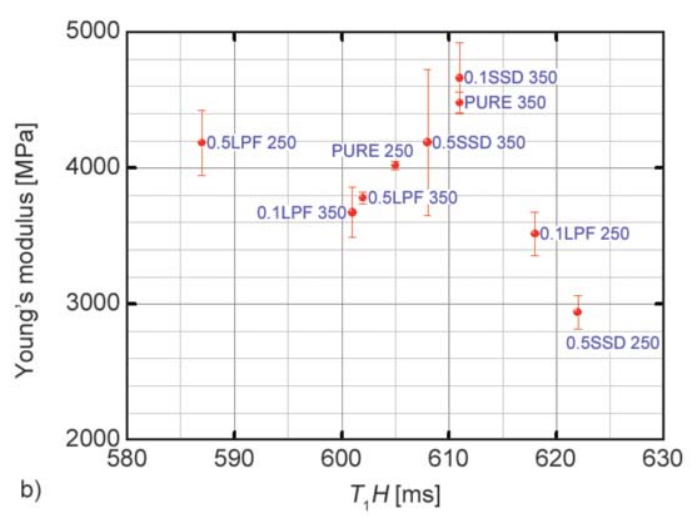

Figure 13. Spin-lattice relaxation time $\left(T_{1} H\right)$ correlations with: (a) density of aggregates formed into composite and (b) elastic modulus. Samples code: XX YY ZZZ (XX = GO content, YYY = method and ZZZ = screw velocity). 
Table 5. Tomography, LF-NMR and molecular weight data.

\begin{tabular}{|l|c|c|c|c|c|c|}
\hline \multicolumn{1}{|c|}{ Sample } & $\begin{array}{c}\text { VOI } \\
{\left[\mathbf{m m}^{3}\right]}\end{array}$ & $\begin{array}{c}\text { Particle volume } \\
{[\mathbf{v} \%]}\end{array}$ & $\begin{array}{c}\text { Particle density } \\
{\left[\mathbf{p a r t i c l e s} / \mathbf{m m}^{3}\right]}\end{array}$ & $\begin{array}{c}\boldsymbol{T}_{\mathbf{1}} \boldsymbol{H} \\
{[\mathbf{m s}]}\end{array}$ & $\begin{array}{c}\overline{\boldsymbol{M}}_{\mathbf{n}} \\
{[\mathbf{D a}]}\end{array}$ & $\begin{array}{c}\overline{\boldsymbol{M}}_{\mathbf{w}} \\
{[\mathbf{D a}]}\end{array}$ \\
\hline 0.1 SSD 350 & 7.628 & 0.029 & 39.066 & 611 & 76580 & 165830 \\
\hline 0.3 SSD 350 & 4.121 & 0.096 & 767.332 & - & - & - \\
\hline 0.5SSD 350 & 1.159 & 0.007 & 110.378 & 608 & 73670 & 158940 \\
\hline 0.1SSD 250 & 1.946 & 0.028 & 204.996 & - & - & - \\
\hline 0.5SSD 250 & 1.519 & 0.070 & 472.517 & 622 & 82640 & 170840 \\
\hline 0.1LPF 350 & 1.329 & 0.034 & 112.885 & 601 & - & - \\
\hline 0.5LPF 350 & 0.713 & 0.038 & 384.189 & 602 & 83590 & 166990 \\
\hline 0.5LPF 250 & 1.201 & 0.044 & 310.523 & 587 & 80790 & 164150 \\
\hline
\end{tabular}

processed at $250 \mathrm{rpm}$ of $\mathrm{SV}$ is quite similar presenting a shear-thinning behavior (i.e., pseudoplastic behavior), with the shear viscosity decreasing with the shear rate. This behavior is due to the disentangled of the molecular chains and 2D particles alignment/sliding under high shear rate [28]. Furthermore, it should
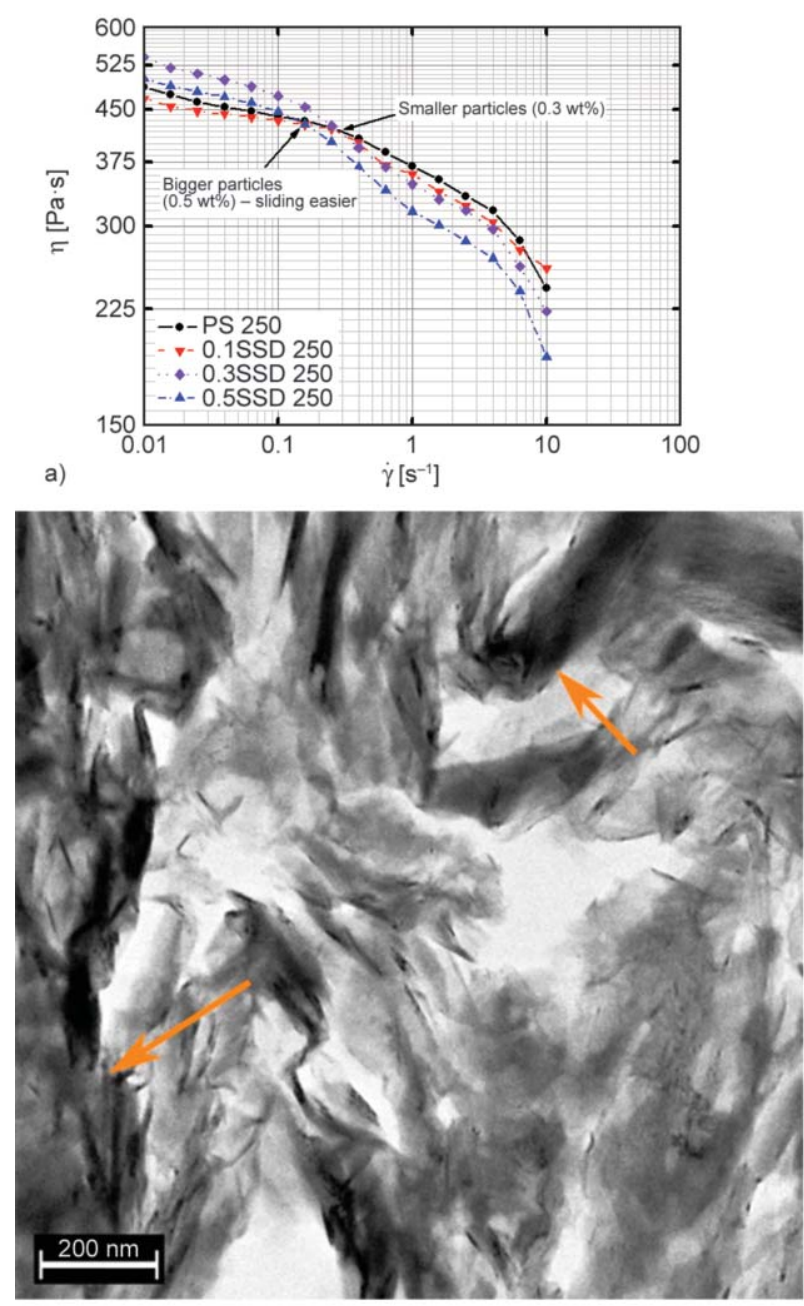

c) be considered that each polymeric chain can present different length, and consequently, the steady shear flow develops alignment/disentanglements of the chains with the increase of the shear rate, therefore, it does not detect a Newtonian plateau region in the experimental shear rate window. Polymeric chains
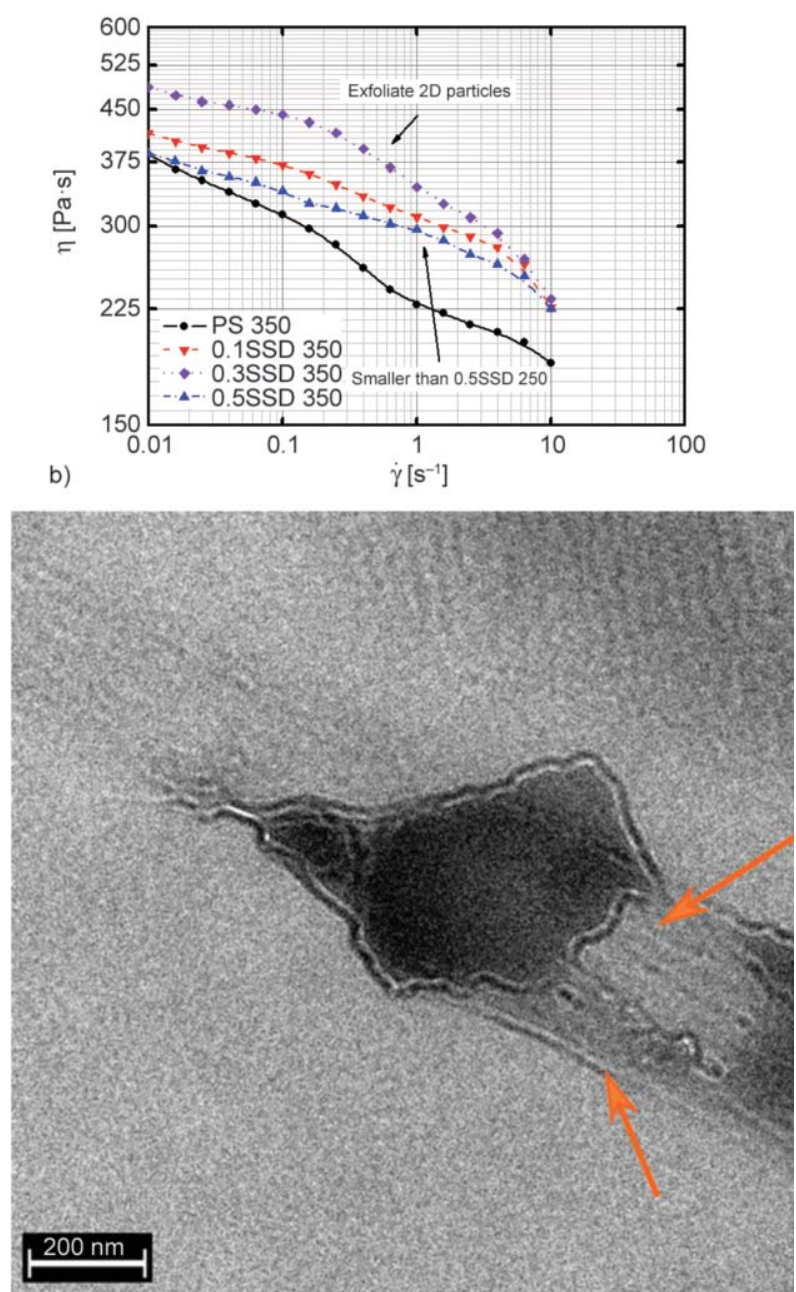

d)

Figure 14. Shear rate dependence of the steady shear viscosity at $230^{\circ} \mathrm{C}$ for polymer pure and its nanocomposites $(0.1,0.3$ and $0.5 \mathrm{wt} \%$ ): (a) SSD at $250 \mathrm{rpm}$ and (b) $350 \mathrm{rpm}$ screw speed. TEM micrographs of the nanocomposites obtained by SSD at $350 \mathrm{rpm}$ screw speed: (c) PS with $0.1 \mathrm{wt} \% \mathrm{GO}$ and (d) PS with $0.3 \mathrm{wt} \%$ GO. Arrows indicates GO sheets. 
and particles arrangement can change during flow process, since entanglements and 2D particles dispersion degree/size are not homogeneous in the melt state, as indicated by the variations in viscosity slope. Note that in Figure 14a, above $0.1 \mathrm{~s}^{-1}$ the shear viscosity for nanocomposites tend to be smaller than pure polymer, which can suggest a lubricant effect provided by the particle $[29,30]$. The graphene oxide dispersed in the polymeric matrix can display some layers stacked, and the lubrication mechanism can be based on the assumption that the GO layers are able to slide over each other with the increase of shear flow, being associated to the cards pack [31-33]. This mechanism is detected in the nanocomposites obtained at lower screw velocity ( $250 \mathrm{rpm}$ ) suggesting a lower exfoliation degree, and occurred at lower shear rate for larger concentration. This observation indicates that the lubricant effect is less evident in the presence of exfoliated particles (nanometric scale) as it is showed in Figure 14b. In this case, there is the intimate contact between the polymeric chains and the exfoliated GO layers, and consequently, it can induce modification in the polymeric relaxation dynamics $[34,35]$. This behavior can be attributed to the formation of a confinement structure of exfoliated GO layers, hindering the disentangling of the polymeric chain during flow, i.e., the exfoliated layers prevents a free-rotation of molecular chains and dissipation of stress, inducing the increase of shear viscosity [36, 37] as observed in Figure 14a. Note that the particles size tend to affect the rheological response, and consequently, affect the final properties of the polymeric nanocomposite. It can be seen that of the screw speed will influence the dispersion and particle size. The transmission electronic microscopy image of the PS nanocomposites with concentration of $0.1 \mathrm{wt} \%$ and processing at $350 \mathrm{rpm}$ screw velocity displayed a distribution of thin graphene oxide layers, as shown in Figure 14c.

One can also observe some regions in which particles layers are folded, as indicated by arrows. In the case of the PS/GO with concentration of $0.3 \mathrm{wt} \%$ (see Figure 14d), the GO layers are parallel to the main plane of the polymeric nanocomposite film, although a few layers are oriented in the other direction. It should also be considered that there are particles in the nanoscale, that cannot be seen, suggesting the high exfoliated level of GO. It is recognized that extruder process parameters are important variables that must be optimized to obtain a high dispersion degree and a final particle size desirable. In general, a great effect of screw velocity was observed that leads to smaller volume particle 2D agglomerates.

These experimental observations lead us to conclude that nanocomposites formed by PS/GO are just viable if particle concentration are low enough to avoid aggregates in micrometric scale. The reason for that is mainly because the high value of surface area for this type of material. The strategies used here for graphene oxide and polystyrene may be also used for manufacture nanocomposites based on other 2D materials and several polymers, as is shown as following.

\subsection{Versatile processing: Testing a new polymer and a new filler}

Twin-screw extruder is one of most versatile processing method for thermoplastics. This kind of machine is designed in modular way, and allows to setup temperature and screw profiles, screw velocity, side feeding, degassing zones etc. In this way, both methods presented here are complementary to extrusion processing by using twin-screw to obtain high level of 2D particles dispersion, being limited by polymer and particle stability to themomechanical-oxidation. In order to show this versatility some additional compositions were studied using different polymers and changing filler. Results from different additional studies are presented as follow.

In order to validate the approach proposed here to obtain polymer/2D material nancomposites, two new systems will be presented. One system is composed of poly (butylene adipate-co-terephthalate) - PBAT and GO, and other is composed of PS and molybdenum disulfide $-\mathrm{MoS}_{2}$. These studies allow validating this method for a different matrix (PBAT) and a different 2D material $\left(\mathrm{MoS}_{2}\right)$. For PBAT/GO composites both methods (SSD and LPF) were performed to prepare $0.1 \mathrm{wt} \%$ GO composites, using GO suspended into ethanol $(0.5 \mathrm{mg} / \mathrm{mL})$ in order to reduced PBAT hydrolysis during the roto-evaporation and processing. The PBAT used was obtained from BASF (Ecoflex F-Blend, C 1200) and it was powdered and dried prior extrusion. In this case no statistically significant change was observed in relation to Young's modulus for the composites obtained by SSD and LPF methods. However, an increase of $26 \%$ in strain at breaking point (SBP) was observed for composite produced using SSD method (Figure 15). This increase in SBP is a good indicative of good dispersion and lubricant effect of GO particles into polymeric matrix. 


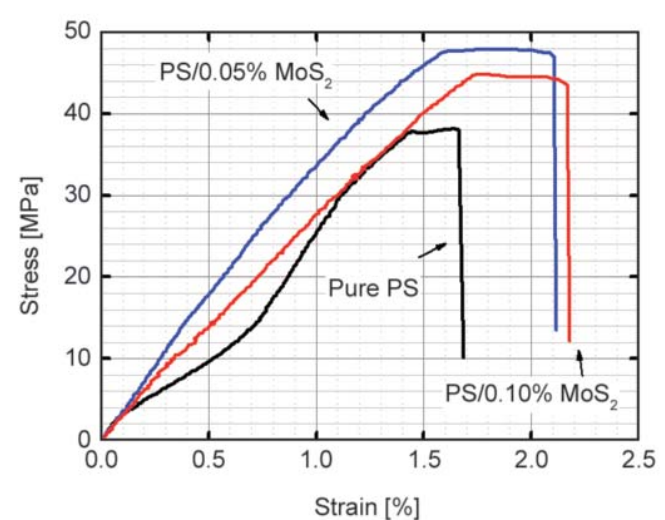

Figure 15. Effect of $\mathrm{MoS}_{2}$ content in tensile-strength of $\mathrm{PS} / \mathrm{MoS}_{2}$ composites.

In case of PS/MoS 2 composite only LPF method was tested because a high $\mathrm{MoS}_{2}$ re-stacking was observed during solvent evaporation. The $\mathrm{MoS}_{2}$ (SigmaAldrich, nominal size particle $<25 \mu \mathrm{m}$ ) particles were exfoliated in water, using a sonication bath, at temperature of $30^{\circ} \mathrm{C}$ by $6 \mathrm{~h}$. Then sonicated suspension was centrifuged at $400 \mathrm{rpm}$ by $1 \mathrm{~h}$ just to remove heavier particles. The composites were produced at 0.05 and $0.10 \mathrm{wt} \%$ of $\mathrm{MoS}_{2}$ using a twin screw extruder operating at the same temperature and screw profiles used for PS/GO composite manufacturing, however a $150 \mathrm{rpm}$ SV were chosen to take advantages of better dispersion observed to LPF at low SV. Mechanical properties (tensile) of the composites were evaluated. According to the data (Figure 16) no difference was observed in Young's Moduli comparing neat PS and composite. However, significant changes in tensile strength (TS) and strain at breaking point (SBP) can be noticed. As can be seen in Figure 16 the insertion of $\mathrm{MoS}_{2}$ lead to an increase in TS and SBP, indicating a good dispersion of particles into PS matrix.

The results of PBAT/GO and PS/MoS 2 indicates that the methodologies proposed here may be not only

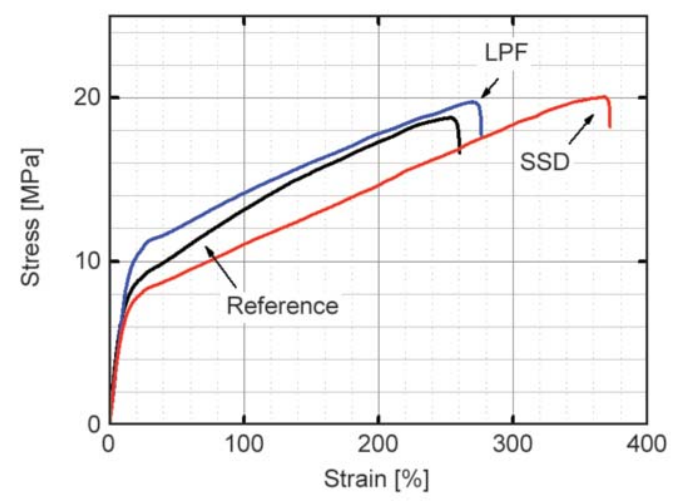

Figure 16. PBAT/GO composites tensile-strength curves. be used for the system PS/GO but may strategically be used to manufacture several other polymer/2D systems. It is important to observe limitation imposed by polymer and filler to choose the correct processing method, thus the proposed methodologies are just the base to improve processing of $2 \mathrm{D}$ filler in polymers.

\section{Conclusions}

Here, for the first time, novel strategies, based on complete studies, showing how a 2D material (graphene oxide) is inserted into the polymeric matrix in order to produce a nanocomposite by using a conventional polymer processing machines leading to large-scale manufacturing is presented. A better understanding of morphology was reached since traditional analysis (mechanical test, molecular weight, rheology, and transmission electron microscopy) and unusual techniques for this type of study (XR-MT and LF-NMR) were used. According to the results presented here, it is possible to obtain high exfoliated degree of $2 \mathrm{D}$ based polymer nanocomposites using pre-exfoliated particles added directly into an extruder (LPF) or deposited on the polymer powder surface (SSD) before extrusion. Using pre-exfoliated 2D material is the key to obtain a good dispersion of particles into the polymer matrix. Both methodologies were used to prepare masterbatches, however, this conventional approach is not indicated for the PS-GO system used here. This is because of the high level of particle aggregation, which occurs during masterbatch production even for $1.0 \% \mathrm{w} / \mathrm{w}$ of content. The reason for that is the high surface area of these particles. The methodologies described here are extendable to all polymers that can be processed using melt mixing. We demonstrate that polymers and 2D materials can be mixed using standard and industrially scalable polymer processing, providing nanocomposites with suitable morphology to obtain desirable properties.

\section{Acknowledgements}

We acknowledge funding from Fundação de Amparo à Pesquisa do Estado de São Paulo (FAPESP), grants 2014/ 22840-3 and 2012/50259-8. This work was also partially funded by Fundo Mackenzie de Pesquisa (MackPesquisa). P.A.R.M. and L. G. A. are supported by a fellowship from FAPESP, 2015/16591-3 and 2017/07244-3, respectively. We also acknowledge the Brazilian Nanotechnology National Laboratory (LNNano) for the X-ray Microtomography analysis. 


\section{References}

[1] Novoselov K. S., Geim A. K., Morozov S. V., Jiang D., Zhang Y., Dubonos S. V., Grigorieva1 I. V., Firsov A. A.: Electric field effect in atomically thin carbon films. Science, 306, 666-669 (2004).

https://doi.org/10.1126/science.1102896

[2] Kim H., Abdala A. A., Macosko C. W.: Graphene/polymer nanocomposites. Macromolecules, 43, 6515-6530 (2010).

https://doi.org/10.1021/ma100572e

[3] Potts J. R., Dreyer D. R., Bielawski C. W., Ruoff R. S.: Graphene-based polymer nanocomposites. Polymer, 52, 5-25 (2011).

https://doi.org/10.1016/j.polymer.2010.11.042

[4] Zhao X., Zhang Q., Chen D., Lu P.: Enhanced mechanical properties of graphene-based poly(vinyl alcohol) composites. Macromolecules, 43, 2357-2363 (2010). https://doi.org/10.1021/ma902862u

[5] Yousefi N., Gudarzi M. M., Zheng Q., Lin X., Shen X., Jia J., Sharif, F., Kim J-K.: Highly aligned, ultralargesize reduced graphene oxide/polyurethane nanocomposites: Mechanical properties and moisture permeability. Composites Part A: Applied Science and Manufacturing, 49, 42-50 (2013).

https://doi.org/10.1016/j.compositesa.2013.02.005

[6] Kim H., Miura Y., Macosko C. W.: Graphene/polyurethane nanocomposites for improved gas barrier and electrical conductivity. Chemical of Materials, 22, 34413450 (2010).

https://doi.org/10.1021/cm100477v

[7] Pokharel P., Lee D. S.: Thermal and mechanical properties of reduced graphene oxide/polyurethane nanocomposite. Journal of Nanoscience and Nanotechnolog, 14, 5718-5721 (2014).

https://doi.org/10.1166/jnn.2014.8824

[8] Kuilla T., Bhadra S., Yao D., Kim N. H., Bose S., Lee J. H.: Recent advances in graphene based polymer composites. Progress in Polymer Science, 35, 1350-1375 (2010).

https://doi.org/10.1016/j.progpolymsci.2010.07.005

[9] Novoselov K. S., Jiang D., Schedin F., Booth T. J., Khotkevich V. V., Morozov S. V., Geim A. K.: Two-dimensional atomic crystals. Proceedings of the National Academy of Sciences, 102, 10451-10453 (2005). https://doi.org/10.1073/pnas.0502848102

[10] Ramanathan T., Abdala A. A., Stankovich S., Dikin D. A., Herrera-Alonso M., Piner R. D., Adamson D. H., Schniepp H. C., Chen X., Ruoff R. S., Nguyen S. T., Aksay I. A., Prud'Homme R. K., Brinson L. C.: Functionalized graphene sheets for polymer nanocomposites. Nature Nanotechnology, 3, 327-331 (2008). https://doi.org/10.1038/nnano.2008.96

[11] Du J., Cheng H. M.: The fabrication, properties, and uses of graphene/polymer composites. Macromolecular Chemistry and Physics, 213, 1060-1077 (2012).

https://doi.org/10.1002/macp.201200029
[12] Fechine G. J. M., Rabello M. S., Souto-Maior R. M.: The effect of ultraviolet stabilizers on the photodegradation of poly(ethylene terephthalate). Polymer Degradation and Stability, 75, 153-159 (2002). https://doi.org/10.1016/S0141-3910(01)00214-2

[13] Al-Itry R., Lamnawar K., Maazouz A.: Improvement of thermal stability, rheological and mechanical properties of PLA, PBAT and their blends by reactive extrusion with functionalized epoxy. Polymer Degradation and Stability, 97, 1898-1914 (2012). https://doi.org/10.1016/j.polymdegradstab.2012.06.028

[14] Stankovich S., Dikin D. A., Piner R. D., Kohlhaas K. A., Kleinhammes A., Jia Y., Wu Y., Nguyen S. T., Ruoff R. S.: Synthesis of graphene-based nanosheets via chemical reduction of exfoliated graphite oxide. Carbon, $\mathbf{4 5}$, 1558-1565 (2007). https://doi.org/10.1016/j.carbon.2007.02.034

[15] Shen J., Shi M., Li N., Yan B., Ma H., Hu Y., Ye M.: Facile synthesis and application of Ag-chemically converted graphene nanocomposite. Nano Research, 3, 339-349 (2010). https://doi.org/10.1007/s12274-010-1037-x

[16] de Oliveira C. F. P., Muñoz P. A R., dos Santos M. C., Medeiros G. S., Simionato A., Nagaoka D. A., de Souza E. A. T., Domingues S. H., Fechine G. J. M.: Tuning of surface properties of poly(vinyl alcohol)/graphene oxide nanocomposites. Polymer Composites, in press (2018). https://doi.org/10.1002/pc.24659

[17] Yang H., Li F., Shan C., Han D., Zhang Q., Niu L., Ivaska A.: Covalent functionalization of chemically converted graphene sheets via silane and its reinforcement. Journal of Materials Chemistry, 19, 4632-4638 (2009). https://doi.org/10.1039/b901421g

[18] Wang F., Yin L., Wang Z. X., Xu K., Wang F. M., Shifa A., Huang Y., Jiang C., He J.: Configuration-dependent electrically tunable van der Waals heterostructures based on $\mathrm{MoTe}_{2} / \mathrm{MoS}_{2}$. Advanced Functional Materials, 26, 5499-5506 (2016). https://doi.org/10.1002/adfm.201601349

[19] Kouroupis-Agalou K., Liscio A., Treossi E., Ortolani L., Morandi V., Pugno N. M., Palermo V.: Fragmentation and exfoliation of 2-dimensional materials: A statistical approach. Nanoscale, 6, 5926-5933 (2014).

https://doi.org/10.1039/C3NR06919B

[20] Liscio A., Kouroupis-Agalou K., Betriu X. D., Kovtun A., Treossi E., Pugno N. M., De Luca G., Giorgini L., Palermo V.: Evolution of the size and shape of 2D nanosheets during ultrasonic fragmentation. 2D Materials, 4, 025017/1-025017/8 (2017). https://doi.org/10.1088/2053-1583/aa57ff

[21] El Achaby M., Arrakhiz F. E., Vaudreuil S., Qaiss A. K., Bousmina M., Fassi-Fehri O.: Mechanical, thermal, and rheological properties of graphene-based polypropylene nanocomposites prepared by melt mixing. Polymer Composites, 33, 733-744 (2012). https://doi.org/10.1002/pc.22198 
[22] Jiang X., Drzal L. T.: Reduction in percolation threshold of injection molded high-density polyethylene/exfoliated graphene nanoplatelets composites by solid state ball milling and solid state shear pulverization. Journal of Applied Polymer Science, 124, 525-535 (2012). https://doi.org/10.1002/app.34891

[23] Kim H., Macosko C. W.: Processing-property relationships of polycarbonate/graphene composites. Polymer, 50, 3797-3809 (2009).

https://doi.org/10.1016/j.polymer.2009.05.038

[24] Fang M., Wang K., Lu H., Yang Y., Nutt S.: Covalent polymer functionalization of graphene nanosheets and mechanical properties of composites. Journal of Materials Chemistry, 19, 7098-7105 (2009).

https://doi.org/10.1039/b908220d

[25] Yan D-X., Pang H., Li B., Vajtai R., Xu L., Ren P-G., Wang J-H., Li Z-M.: Structured reduced graphene oxide/ polymer composites for ultra-efficient electromagnetic interference shielding. Advanced Functional Materials, 25, 559-566 (2015). https://doi.org/10.1002/adfm.201403809

[26] Li W., Tang X-Z., Zhang H-B., Jiang Z-G., Yu Z-Z., Du X-S., Mai Y-W.: Simultaneous surface functionalization and reduction of graphene oxide with octadecylamine for electrically conductive polystyrene composites. Carbon, 49, 4724-4730 (2011).

https://doi.org/10.1016/j.carbon.2011.06.077

[27] Oliveira C. F. P., Carastan D. J., Demarquette N. R., Fechine G. J. M.: Photooxidative behavior of polystyrenemontmorillonite nanocomposites. Polymer Engineering and Science, 48, 1511-1517 (2008).

https://doi.org/10.1002/pen.21120

[28] Chen D., Yang H., He P., Zhang W.: Rheological and extrusion behavior of intercalated high-impact polystyrene/organomontmorillonite nanocomposites. Composites Science and Technology, 65, 1593-1600 (2005). https://doi.org/10.1016/j.compscitech.2005.01.011

[29] Rapoport L., Nepomnyashchy O., Verdyan A., PopovitzBiro R., Volovik Y., Ittah B., Tenne R.: Polymer nanocomposites with fullerene-like solid lubricant. Advanced Engineering Materials, 6, 44-48 (2004).

https://doi.org/10.1002/adem.200300512
[30] Pu J., Wan S., Zhao W., Mo Y., Zhang X., Wang L., Xue $\mathrm{Q}$.: Preparation and tribological study of functionalized graphene-IL nanocomposite ultrathin lubrication films on Si substrates. Journal of Physical Chemistry C, 115, 13275-13284 (2011). https://doi.org/10.1021/jp111804a

[31] Wang S., Chen Y., Ma Y., Wang Z., Zhang J.: Size effect on interlayer shear between graphene sheets. Journal of Applied Physics, 122, 074301/1-074301/18 (2017). https://doi.org/10.1063/1.4997607

[32] Areshkin D. A., White C. T.: Building blocks for integrated graphene circuits. Nano Letters, 7, 3253-3259 (2007).

https://doi.org/10.1021/n1070708c

[33] Moghadam A. D., Omrani E., Menezes P. L., Rohatgi P. K.: Mechanical and tribological properties of self-lubricating metal matrix nanocomposites reinforced by carbon nanotubes (CNTs) and graphene - A review. Composites Part B: Engineering, 77, 402-420 (2015). https://doi.org/10.1016/j.compositesb.2015.03.014

[34] Magomedov G. M., Khashirova S. Y., Ramazanov F. K., Beslaneeva Z. L., Mikitaev A. K.: Relaxation properties and structures of polymer nanocomposites based on modified organoclays. Polymer Science Series A, 56, 652-661 (2014). https://doi.org/10.1134/S0965545X14050113

[35] Comer A. C., Heilman A. L., Kalika D. S.: Dynamic relaxation characteristics of polymer nanocomposites based on poly(ether imide) and poly(methyl methacrylate). Polymer, 51, 5245-5254 (2010). https://doi.org/10.1016/j.polymer.2010.08.053

[36] Krishnamoorti R., Vaia R. A., Giannelis E. P.: Structure and dynamics of polymer-layered silicate nanocomposites. Chemistry of Materials, 8, 1728-1734 (1996). https://doi.org/10.1021/cm960127g

[37] Lim Y. T., Park O. O.: Rheological evidence for the microstructure of intercalated polymer/layered silicate nanocomposites. Macromolecular Rapid Communications, 21, 231-235 (2000).

https://doi.org/10.1002/(sici)15213927(20000301)21:5<231::aid-marc231>3.0.co;2-3 